\title{
Contractile Cells in the Human Scleral Spur
}

\author{
ERNST TAMM*a, CASSANDRA FLÜGEL'a, FRITZH. STEFANI' AND JOHANNES W. ROHEN \\ ${ }^{a}$ Department of Anatomy, University of Erlangen-Nürnberg and ${ }^{\circ}$ Eye Hospital of the University of \\ Munich, Germany
}

(Received Lund 15 March 1991 and accepted in revised form 13 June 1991)

\begin{abstract}
The scleral spur in 37 human (age 17-87 years) and six cynomolgus monkey eyes (2-4 years) was investigated. Serial meridional and tangential sections were studied with ultrastructural and immunocytochemical methods. The bundles of the ciliary muscle do not enter the scleral spur, but their tendons, which consist of elastic fibres join the elastic fibres in the scleral spur. Within the scleral spur a population of circularly oriented and spindle-shaped cells is found. In contrast to the ciliary muscle cells, the scleral spur cells form no bundles, but are loosely aggregated. They have long cytoplasmic processes and are connected to each other by adherens-type and gap junctions. They stain intensely for $\alpha$-smooth muscle actin, myosin and vimentin. In contrast to the ciliary muscle cells, they do not stain for desmin. Ultrastructurally, the scleral spur cells contain abundant thin (actin) filaments, but do not otherwise show the typical ultrastructural features of ciliary muscle cells. The scleral spur cells do not express a complete basal lamina. They form individual tendinous connections with the clastic fibres in the sclcral spur, which are continuous with the elastic fibres of the trabecular meshwork. The scleral spur cells are in close contact with nerve terminals containing small agranular $(30-60 \mathrm{~nm})$ and large granular $(65-110 \mathrm{~nm})$ vesicles but also with terminals containing small granular (30-60 nm) vesicles which are regarded as typical for adrenergic terminals. We conclude that the scleral spur cells are contractile myofibroblasts. Their contraction might influence the rate of the aqueous outflow.

Key words: scleral spur; myofibroblasts; ultrastructure ; immunocytochemistry ; $\alpha$-sm-actin ; myosin: desmin; vimentin; ciliary muscle; elastic fibres; nerve terminals.
\end{abstract}

\section{Introduction}

It has been demonstrated both in rhesus monkeys (Flocks and Zweng, 1957) and in humans (Rohen and Unger, 1958, 1959: Rohen 1964: Grierson. Lee and Abraham, 1978) that contraction of the ciliary muscle displaces the scleral spur posteriorly and internally. which in turn causes a separation of the trabecular meshwork lamellae. Rohen et al. (1981) described a network of elastic-like fibres underneath the endothelial lining of Schlemm's canal (cribriform plexus). which is directly connected with the tendons of the ciliary muscle and the elastic-like fibres in the scleral spur. Contraction of the ciliary muscle and displacement of the scleral spur might not only separate the trabecular lamellae but also, more importantly, influence the area of the outflow pathways in the cribriform layer and so modulate the outflow resistance. In fact, if the ciliary muscle is removed from its anterior attachment to the scleral spur and the trabecular meshwork, pilocarpine no longer affects the outflow facility (Kaufman and Bárány, 1976).

In the present study, we have investigated the scleral spur and the anterior attachment of the ciliary muscle in humans and monkeys with ultrastructural and immunocytochemical methods. We report on a hitherto neglected population of loosely arranged and

\footnotetext{
* For correspondence at: Anatomisches Institut, Lehrstuhl II der Universität Erlangen-Nürnberg. Krankenhausstr. 9. 8520 Erlangen. Germany.
}

equatorially oriented cells present throughout the scleral spur. These scleral spur cells (SSC) show ultrastructural and immunocytochemical differences from ciliary muscle cells, but resemble contractile myofibroblasts. They form tendinous connections with the elastic-like fibres of the scleral spur, which are continuous with the elastic-like fibres of the trabecular meshwork. Although their functional significance is not yet clear, contraction of the SSC might influence the rate of aqueous outflow.

\section{Material and Methods}

Twelve pairs of human autopsy eyes (six pairs derived from donors aged 17-34 years old and six pairs from donors aged 64-87 years old) and 25 human eyes (18-54 years), enucleated because of posterior choroidal melanoma, were investigated. The autopsy eyes were enucleated 6-12 hr after death. The melanoma eyes were obtained from the Eye Hospital of the University of Munich, Germany. None of the donors had a history of abnormalities in the chamber angle.

In addition, the eyes of six cynomolgus monkeys (Macaca fascicularis, age 2-4 years) were investigated. The animals were killed in conjunction with various non-ocular experimental protocols. The eyes were enucleated from the anaesthetized animals. Anaesthesia for in vivo enucleation was ketamine $\mathrm{HCl}$ $15 \mathrm{mg} \mathrm{kg}^{-1}$ (i.m.), followed by pentobarbital $\mathrm{Na}$ $30 \mathrm{mg} \mathrm{kg}^{-1}$ body weight (i.m.). The animals were 

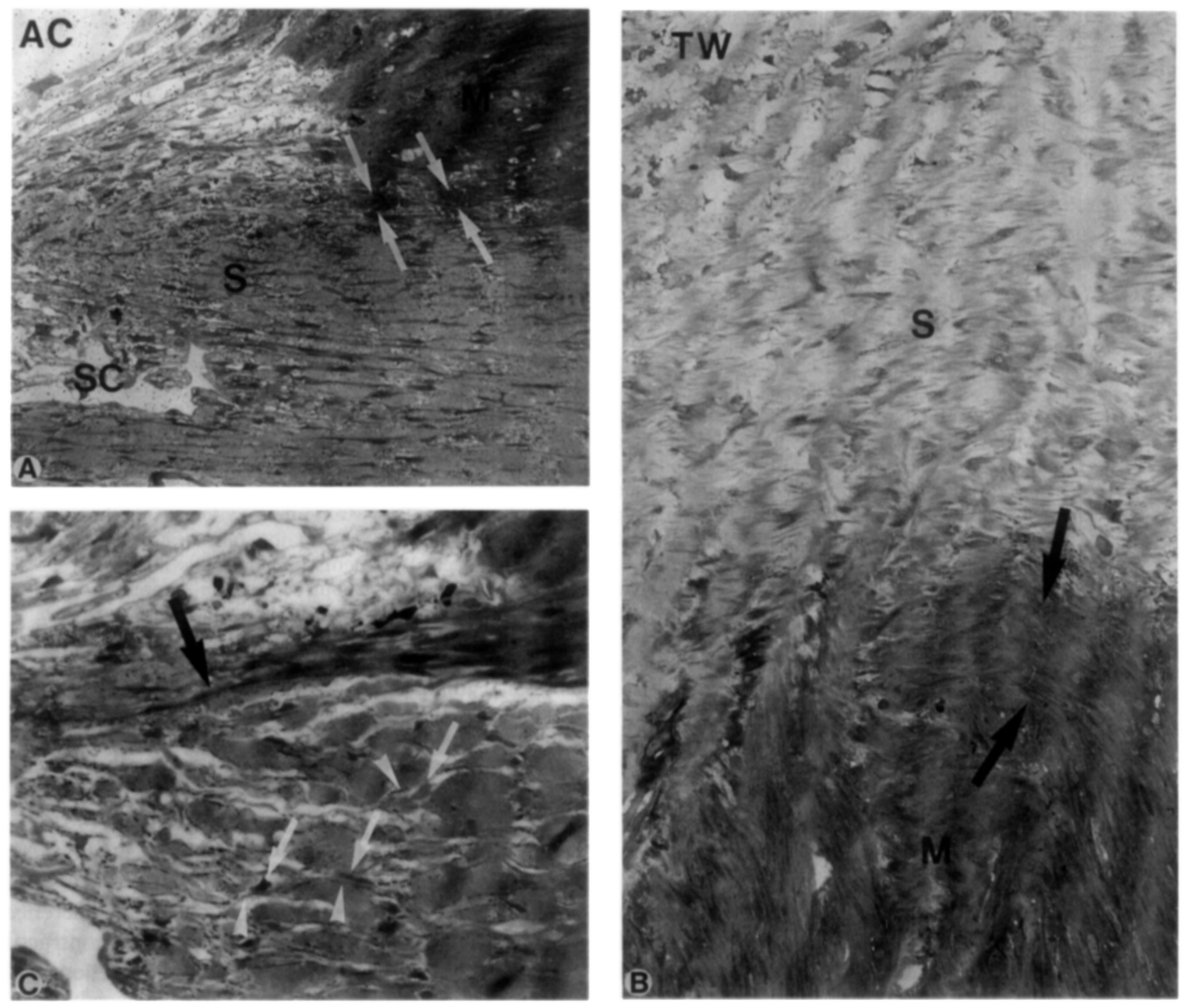

FIG. 1. Semithin sections of the scleral spur and the anterior insertion of the ciliary muscle (human eye, 24 years). A, Near the insertion of the muscle to the scleral spur, circularly oriented ciliary muscle bundles are seen (arrows): S, scleral spur: SC, Schlemm's canal; AC, anterior chamber; M, ciliary muscle (meridional section). $\times 320$. B. The same region of the same specimen as in (A), cut tangentially. Near its insertion to the scleral spur, a muscle bundle of the meridional portion bends in the circular direction (arrows): S, scleral spur; TW, trabecular meshwork; M, ciliary muscle. $\times 320$. C. Some of the tendons of the ciliary muscle pass the inner part of the spur meridionally and continue directly to the trabecular meshwork (black arrow). The scleral spur cells (white arrows) are surrounded by numerous elastic fibres (arrowheads) which are continuous with the elastic fibres of the trabecular meshwork (meridional section). $\times 640$.

killed by a pentobarbital overdose. These experiments conformed to the ARVO Resolution on the Use of Animals in Research (The Association for Research in Vision and Ophthalmology, 1990).

The human autopsy eyes and the monkey eyes were cut equatorially behind the ora serrata and the anterior segment was dissected in quadrants. From each quadrant, wedge-shaped pieces containing trabecular meshwork and the anterior ciliary muscle were cut and further prepared both for frozen and paraffin light microscopical sectioning and for electron microscopy.

For frozen sections, at least one piece from each quadrant was quick-frozen in isopentane, pre-cooled with liquid nitrogen. Meridional and serial tangential sections $(10 \mu \mathrm{m})$ were cut through the chamber angle at $-20^{\circ} \mathrm{C}$. The sections were placed onto slides covered with chrome-alum-gelatine, and fixed in acetone for $10 \mathrm{~min}$ at $-20^{\circ} \mathrm{C}$. After fixation, the sections were processed for immunocytochemistry.

For paraffin sections, picces from each quadrant were fixed in paraformaldehyde-lysine-perjodate (PLP) solution (McLean and Nakane, 1974) for $4 \mathrm{hr}$ at $4^{\circ} \mathrm{C}$. After washing in PBS, the material was dehydrated through an alcohol gradient and embedded in paraffin. Meridional sections, as well as serial tangential sections through the chamber angle were cut $5 \mu \mathrm{m}$ thick and mounted on $0.1 \%$ poly-L-lysine-coated slides. The sections were either stained with a combined Weigert's resorcin-fuchsin/Goldner stain (Romeis, 1989) or further processed for immunocytochemistry.

For electron microscopy, pieces from each quadrant were fixed in Ito's solution (Ito and Karnovsky. 1968). 

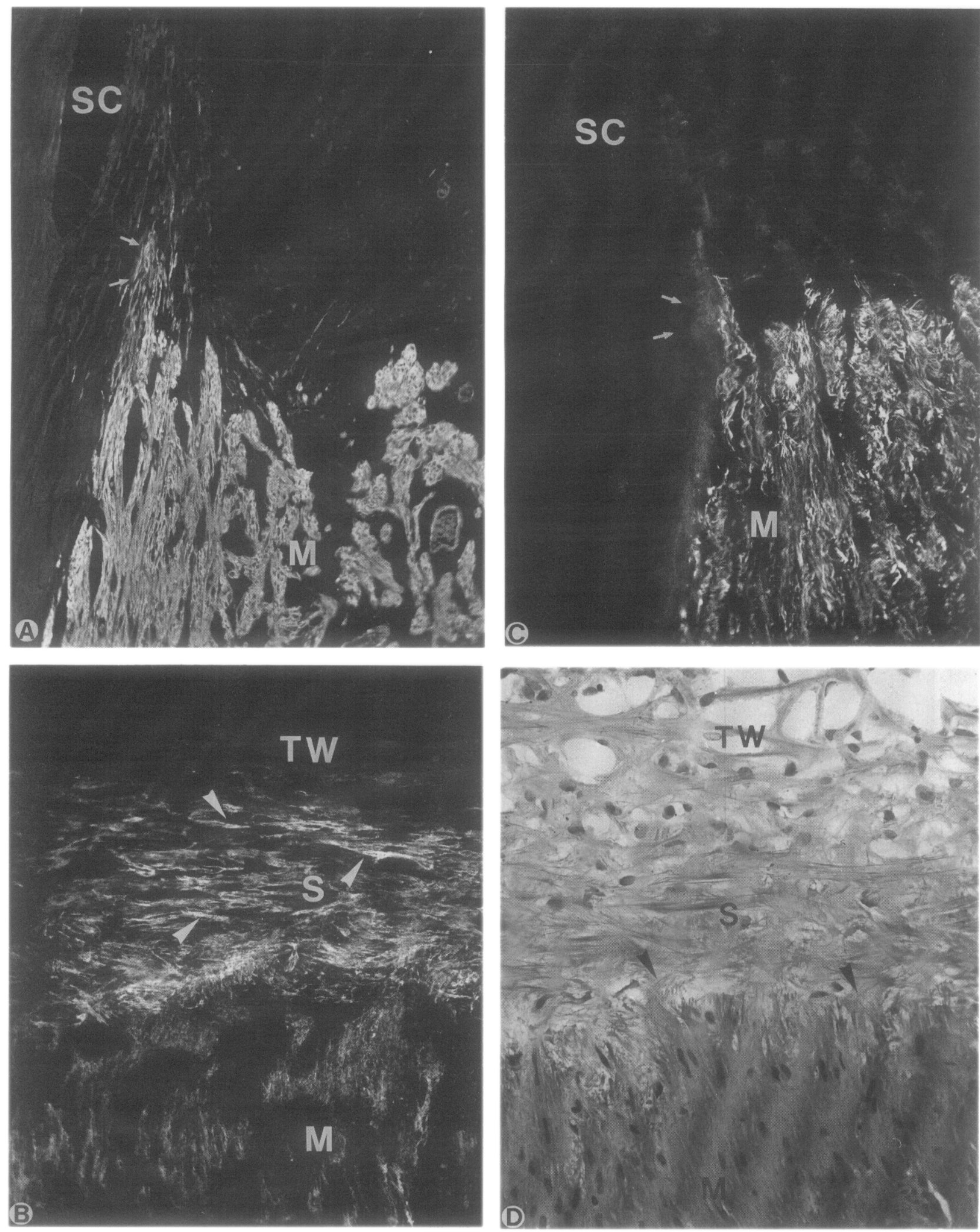

FIG. 2. Immuncytochemistry of the scleral spur of a human eye (65 years). A, Ciliary muscle cells (M) and vascular muscle cells stain positive with antibodies against $\alpha$-sm-actin. Arrows indicate the scleral spur, where all cells stain brightly positive for $\alpha$-sm-actin: SC, Schlemm's canal (meridional paraffin section). $\times 170$. B. Tangential section of scleral spur and ciliary muscle stained for $\alpha$-sm-actin. The plane of the section is the same as in (D). Positively stained cells oriented in a circular direction are seen throughout the entire spur tissue (arrows). While ciliary muscle cells also stain positive, no staining is seen in the trabecular meshwork in this specimen (paraffin section). $\times 320$. C. Immunostaining with antibodies against desmin. Ciliary muscle cells stain brightly positive, whereas the scleral spur (arrows) does not stain for desmin (meridional frozen section). $\times 170$. D. Conventional stained tangential section of scleral spur and ciliary muscle, same region as in (B). The ciliary muscle bundles insert by means of elastic tendons which form arcades finally bending in a circular direction (arrowheads). TW. Trabecular meshwork: S. scleral spur: M. ciliary muscle. (Semithin section). $\times 320$. 

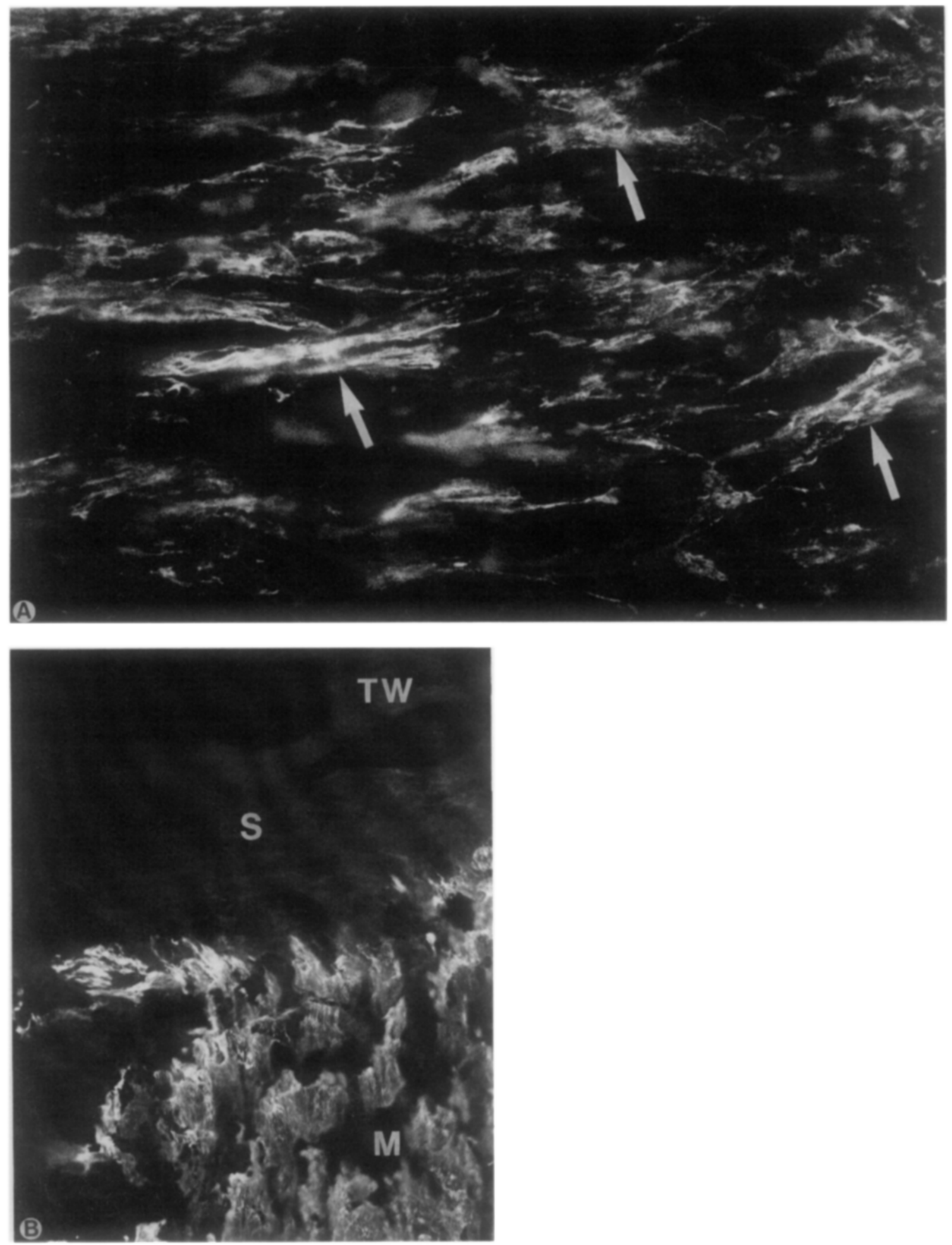

Fig. 3. Immunocytochemistry of the scleral spur of a human eye. A. High magnification of a tangential section of the scleral spur cells (arrows) after staining for $\alpha$-sm-actin. The cell body and the long cytoplasmic processes stain positive (paraffin section). $\times 1000 . B$, Tangential section of scleral spur and ciliary muscle after staining for desmin. The plane of the section is the same as in Fig. 2(B) and (D). Ciliary muscle cells (CM) stain brightly positive, whereas the cells of the scleral spur (S) remain unstained. At its insertion to the spur, a ciliary muscle bundle bends in the circular direction. TW. Trabecular meshwork. (Frozen section). $\times 320$.

Fic. 4. Electron microscopy of the scleral spur cells. A, The cells (asterisks) are in close contact with the elastic-like fibres (arrows) of the scleral spur (meridional section). $\times 6000$. B. Tangential section of a scleral spur cell (SSC). Same region of the same specimen as in (A). The cytoplasm of the cell is filled with abundant $6-7-\mathrm{nm}$ thin filaments which run parallel to the long axis of the cell. The cell membrane shows numerous membrane-bound caveolae (arrowheads). The cell is surrounded by the $50-\mathrm{nm}$ sheath material (asterisks) of the elastic-like fibres. $\times 33600 . \mathrm{C}$. The scleral spur cells are connected by gap junctions (arrow). $\times 161500$. 

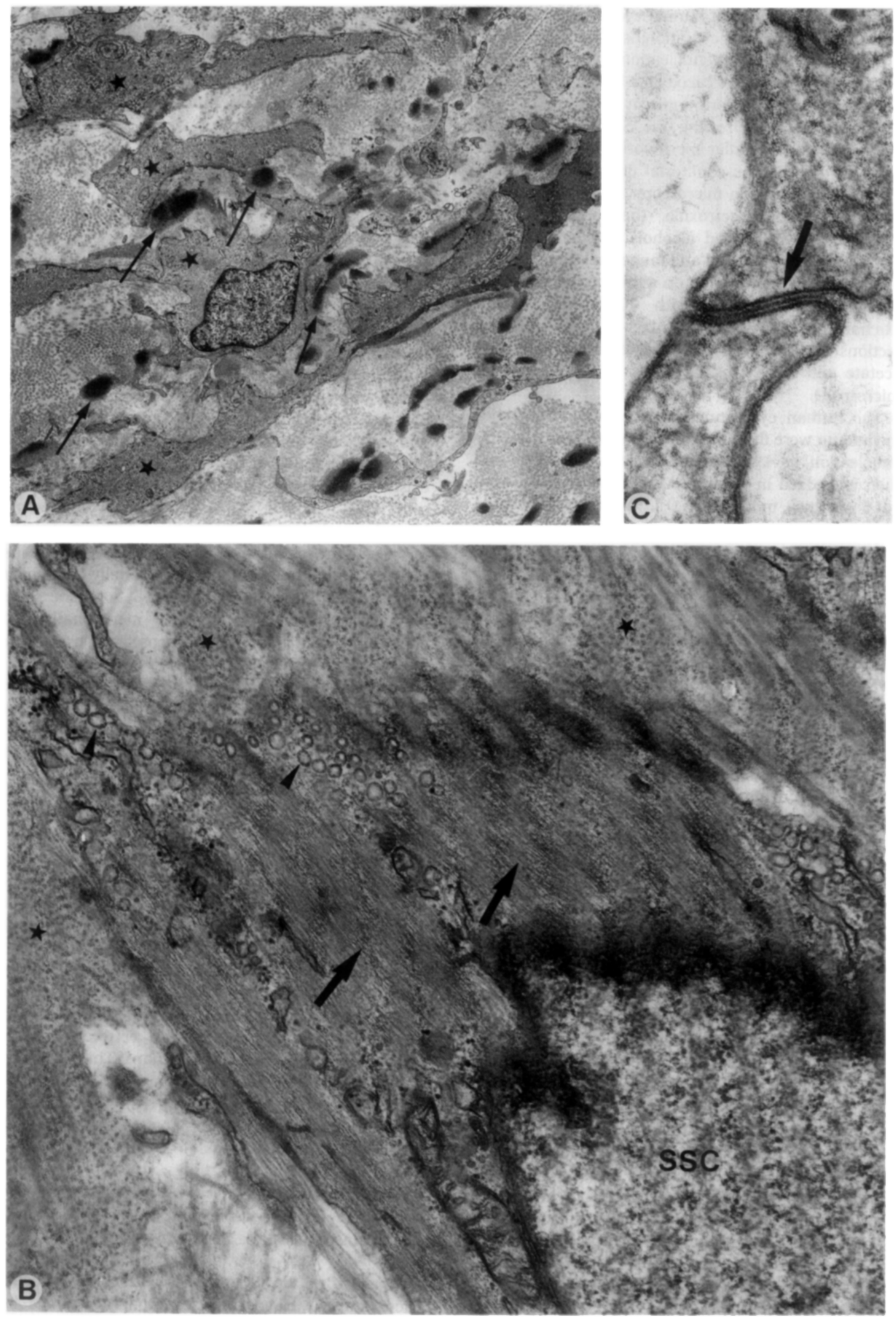

Fig. 4. For legend see facing page. 
In addition, two pairs of human eyes (age 27 and 81 years) and two pairs of cynomolgus monkey eyes (age 2 years) were fixed after enucleation by infusion of $3 \%$ glutaraldehyde in $0 \cdot 1 \mathrm{M}$ cacodylate buffer, $\mathrm{pH} 7 \cdot 2$, into the anterior chamber for $60 \mathrm{~min}$ at a pressure of some $10 \mathrm{mmHg}$ above the resting one. Small pieces (width $1 \mathrm{~mm}$ ) of the trabecular meshwork and the anterior ciliary muscle in the equatorial direction were then processed for electron microscopy. After post-fixation with $1 \%$ osmium tetroxide. the specimens were dehydrated with graded alcohols and embedded in Epon. Meridional, frontal and tangential semithin and ultrathin sections were cut on a microtome. Semithin sections were stained with Richardson's stain (Richardson, Jarret and Finke, 1960). Ultrathin sections were treated with lead citrate and uranyl acetate and viewed using a Zeiss EM 902 electron microscope.

The human eyes enucleated because of posterior melanoma were fixed as whole eyes immediately after enucleation in $4 \%$ buffered formalin for $24 \mathrm{hr}$ and then embedded in paraffin. Meridional sections were cut $5 \mu \mathrm{m}$ thick, mounted on $0.1 \%$ poly-L-lysine-coated slides and further processed for immunocytochemistry.

\section{Immunocytochemistry}

After fixation and drying at room temperature, the frozen sections were pre-incubated for $45 \mathrm{~min}$ in Blotto's dry milk solution (Duhamel and Johnson, 1985). The paraffin sections were deparaffinized and pre-incubated for $20 \mathrm{~min}$ in normal rabbit serum $(5 \%$ in PBS).

After pre-incubation, both frozen and paraffin sections were incubated with the primary antibody for $90 \mathrm{~min}$. For demonstration of the intermediate filament desmin, monoclonal mouse antibodies from Dakopatts (Hamburg, FRG) were used [clone DE-R-11, anti-swine IgG1 (Debus, Weber and Osborn, 1983) and clone D33, antihuman IgG1] both in a dilution of $1: 50$. For vimentin, a monoclonal mouse anti-swine antibody from Dakopatts [clone V9. IgG1 (Osborn, Dcbus and Weber, 1984)] was applied to the slides at a dilution of $1: 5$. The antibodies were diluted in $0 \cdot 1 \mathrm{M}$ PBS, at a pH of $7 \cdot 2-7 \cdot 4$. Demonstration of $\alpha$-smooth muscle (sm)-actin was performed using a monoclonal mouse antibody to smooth muscle specific $\alpha$-sm-actin from Sigma [St Louis, MO, U.S.A.; clone no. 1A4, IgG2a (Skalli et al., 1986)]; diluted in PBS $(1: 150)$ with $1 \%$ bovine serum albumin (Sigma). For demonstration of smooth muscle myosin a polyclonal rabbit anti-bovine antibody to skeletal and smooth muscle myosin from Sigma, diluted in PBS (1:5) with $1 \%$ bovine serum albumin, was used. Each incubation was performed in a moist chamber at room temperature. The sections were washed three times with PBS, each for $10 \mathrm{~min}$ and incubated with fluorescein or rhodamine-labelled rabbit-anti-mouse IgG (Dakopatts) diluted with PBS $(1: 20)$. After washing again three times in PBS, the sections were mounted in Entellan (Merck, Darmstadt, FRG) containing 2.5\% 1,4-diazobicyclo-octane (Merck; Johnson et al., 1982). Control experiments were performed using either PBS or a mouse pre-immune serum instead of the primary antibody.

\section{Results}

\section{Light Microscopy}

The connective tissue of the scleral spur consists of both collagen fibres and numerous interspersed elastic fibres. Both groups of fibres predominantly run in an equatorial direction. Between these fibres, elongated and loosely aggregated scleral spur cells (SSC) are seen. These also show an equatorial orientation. Immediately behind the scleral spur, the outermost meridional ciliary muscle bundles form small arcades by bending in the circular direction, both clockwise and anticlockwise. These circular muscle bundles do not enter the spur, but their tendons, which consist of elastic fibres, join the elastic fibre system of the scleral spur [Figs 1(A) and (B)]. Further inward, the meridional muscle bundles do not bend, but run straight forward to the scleral spur. There they insert by means of elastic tendons which form arches finally bending in an equatorial direction [Fig. 2(D)]. Some of these tendons, however, pass the spur meridionally and continue directly to the corneoscleral trabecular meshwork [Fig. 1(C)].

The general architecture of the scleral spur and the ciliary muscle insertion is similar in both cynomolgus monkeys and humans. In cynomolgus monkeys, however, the scleral spur is smaller than in human eyes.

\section{Immunocytochemistry}

Alpha-smooth-muscle-actin ( $\alpha$-sm-actin). A pronounced staining for $\alpha$-sm-actin is seen not only in the ciliary muscle cells, but also in the SSC [Fig. 2(A)]. This is especially evident in tangential sections [Figs 2(C) and 3(A)]. Here, positively stained cells, mainly oriented in an equatorial direction, are seen throughout the entire spur tissue. Due to the smaller size of the monkey scleral spur, the number of positively stained cells in the spur is smaller; the distance between them is approximately the same as in humans. The outermost ciliary muscle bundles, which bend in the circular direction, stain with the same intensity as the rest of the ciliary muscle. The staining pattern is the same in frozen and paraffin sections.

Myosin (skeletal and smooth). The staining pattern for myosin is comparable with $\alpha$-sm-actin as only ciliary muscle cells and SSC stain positive.

Vimentin. All the SSC, the fibroblasts in the adjacent sclera and the ciliary muscle fibroblasts stained for 


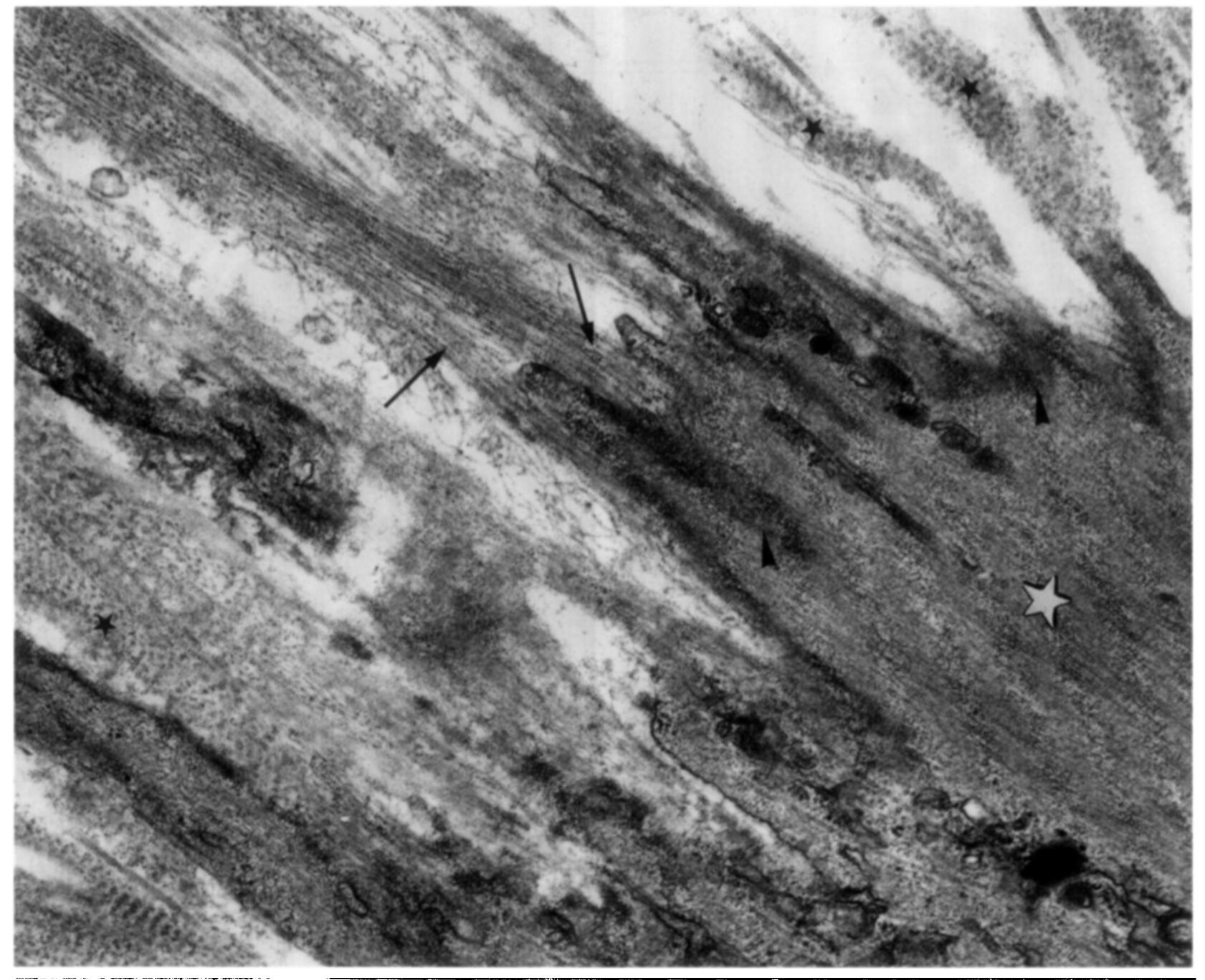

Fig. 5. The cytoplasmic processes of the scleral spur cells form tendon-like structures with the elastic-like fibres in the scleral spur. The microfibrils of the elastic-like fibres and the $50-\mathrm{nm}$ banded sheath material (asterisks) approach thc cell mcmbranc of the scleral spur cells and the valleys between them (arrows). In the region of contact, the cell membrane forms dense bands (arrowheads) where the intracellular 6-7 nm thin filaments attach. (Electron micrograph, tangential section.) $\times 32400$.

vimentin in paraffin sections. Ciliary muscle cells are not stained in paraffin sections; they only stain weakly positive in frozen sections.

Desmin. Both in human and in monkcy eyes desmin staining is only seen in ciliary muscle cells. No staining is seen in the SSC [Figs 2(B) and 3(B)] either in frozen or in paraffin sections.

\section{Electron Microscopy}

Eyes of young humans (17-34 years). The collagen fibres in the scleral spur form dense, equatorially oriented bundles. The individual fibres have diameters of $30-50 \mathrm{~nm}$ and a typical periodicity of $64 \mathrm{~nm}$. Interposed between. and running parallel to the collagen bundles, is a network of numerous elastic fibres. They are ultrastructurally similar to the elastic fibres previously described in the chamber angle tissues [Fig. 4(A)] (Iwamoto, 1964; Vegge and
Ringvold, 1971; Lütjen-Drecoll, Futa and Rohen, 1981). They comprise an electron-dense amorphous central core and a sheath consisting of microfibrils and cross-banded material with a periodicity of 50-60 nm [Figs 4(A) and (B)]. Shcath matcrial with a 100-nm periodicity is only occasionally observed in the fibres of the scleral spur.

The scleral spur cells (SSC) are oriented parallel to the bundles of collagenous and elastic fibres in the scleral spur [Fig. 4(A)]. They are elongated spindleshaped cells with a flat cell body and long irregular cytoplasmic processes. The cytoplasm is filled with abundant $6-7 \mathrm{~nm}$ thin filaments, which run parallel to the long axis of the cell [Fig. 4(B)]. Between the filaments there are small dense bodies and sparse mitochondria. In the vicinity of the nucleus, profiles of smooth endoplasmic reticulum and Golgi membranes are seen. The cell membrane shows numerous membrane-bound caveolae [Fig. 4(B)]. The cells are often connected to each other by adherens-type and gap junctions occurring mainly between the cyto- 

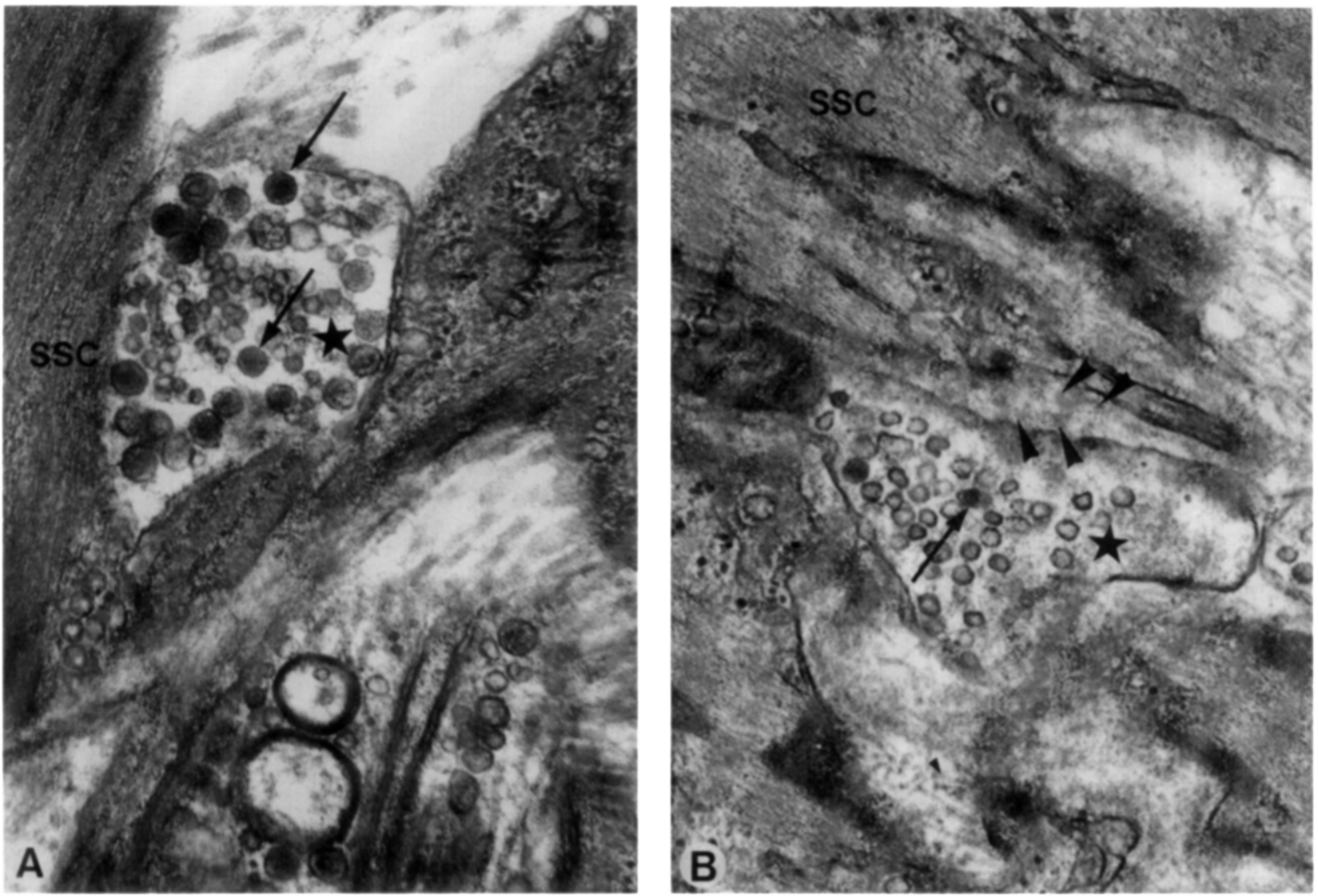

Fig. 6. Nerve terminals in the scleral spur. A, Nerve terminal containing both small agranular $(30-60 \mathrm{~nm})$ and large granular vesicles $(65-100 \mathrm{~nm})$ which is located very close to an adjacent scleral spur cell (SSC) without intervening basal lamina. B, Nerve terminal containing small agranular $(30-60 \mathrm{~nm})$ and small granular $(30-60 \mathrm{~nm})$ vesicles. The terminal is separated from the scleral spur cells (SSC) by a gap of approximately $100 \mathrm{~nm}$, in which two layers of basal lamina (arrowheads) are present. $\times 48000$.

plasmic processes [Fig. 4(C)]. The cytoplasmic processes of the cells are in close contact with the elastic-like fibres [Figs $4(A),(B)$ and 5]. In these areas of contact the cell membrane shows dense bands, so that often tendon-like structures are formed similar to the myotendinous junction in striated muscle. This is especially evident in tangential sections. The microfibrils of the elastic-like fibres, and the 50-nm banded sheath material approach the cell membrane of the cytoplasmic processes and the valleys between them. They are connected with the cell membrane by fine fibrillar material (Fig. 5). Occasionally also collagen fibrils with a diameter of $30 \mathrm{~nm}$ and the typical periodicity of $64 \mathrm{~nm}$ are seen in close contact with the cell membrane of the SSC. Adjacent to the cell membrane. in the region of the tendinous junctions and in areas where dense bands are formed, an incomplete basal lamina is seen. In the vicinity of the scleral spur cells, nerve fibres and nerve fibre terminals are found. Two types of terminals can be distinguished: those containing both small agranular $(30-60 \mathrm{~nm})$ and large granular (65-100 $\mathrm{nm}$ ) vesicles; and terminals with both small agranular and small granular $(30-60 \mathrm{~nm}$ ) vesicles [Figs 6(A) and (B)]. The terminals are separated from the SSC by a gap of approximately $100 \mathrm{~nm}$ in which two layers of basal lamina are present. one close to the nerve terminal and the other close to the SSC [Fig. 6(B)]. Some of the terminals, however, are located very close to an adjacent SSC without an intervening basal lamina [Fig. $6(\mathrm{~A})]$.

In contrast to the SSC, the ciliary muscle cells of the meridional portion are closely aggregated into bundles in the region of their attachment to the scleral spur. This is also the case for those muscle bundles which form arcades by bending in the circular direction. Within the bundles, the muscle cells are separated from each other only by their complete basal lamina and a small amount of extracellular microfibrils, with a diameter of 12-14 $\mathrm{nm}$. In addition, numerous nerve fibres and nerve endings containing small agranular. and occasionally one or two large granular vesicles, are seen between the individual muscle cells. The cells are connected to each other by adherens-type junctions. Gap junctions are not observed. The ciliary muscle cells show the typical structural characteristics of primate ciliary muscle cells previously described (Ishikawa, 1962; van der Zypen. 1967: LütjenDrecoll, Tamm and Kaufman. 1988).

At their attachment to the scleral spur. the individual ciliary muscle cells taper off and show an irregular profile with invaginations and long cytoplasmic protrusions. Here, the cells form tendinous 


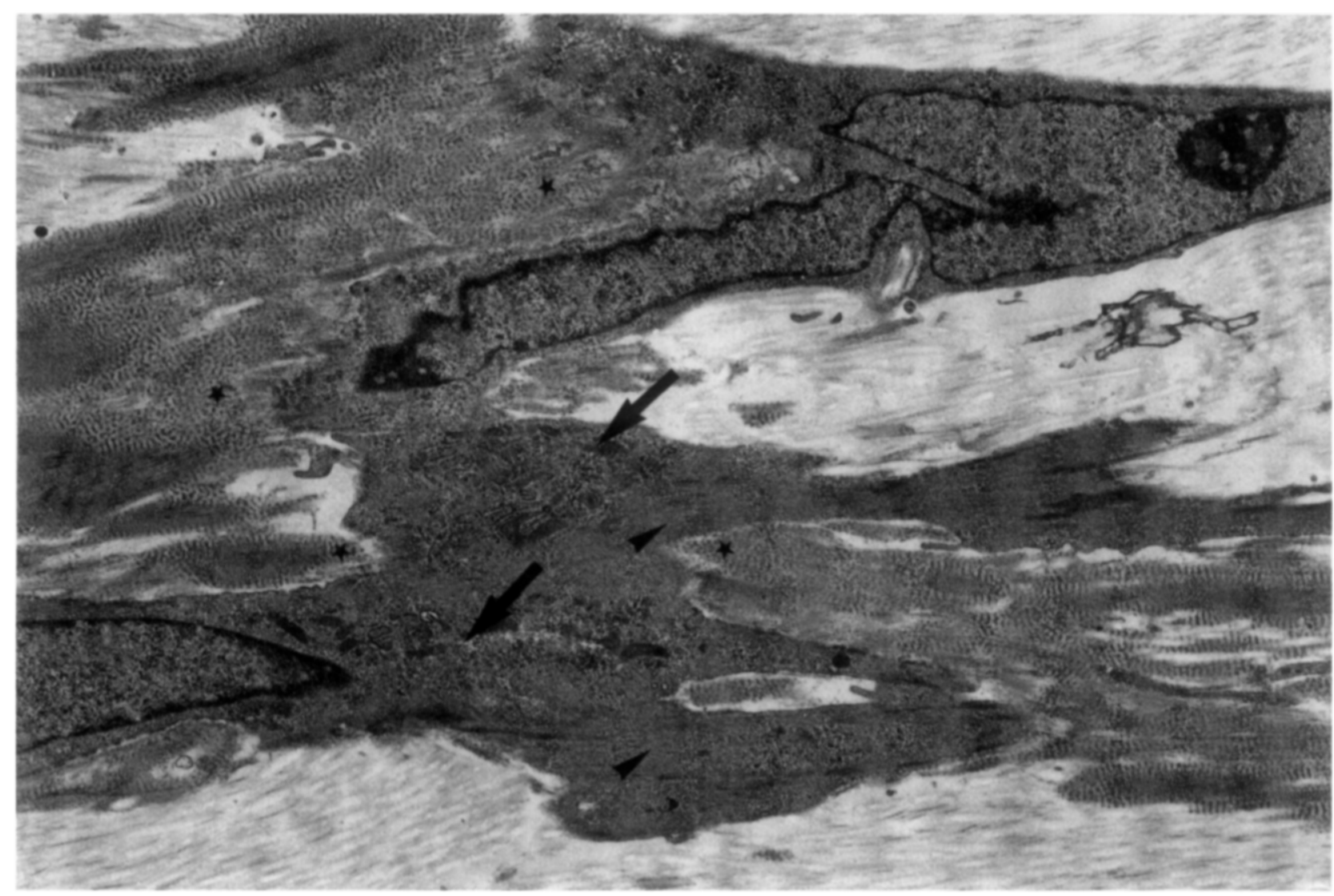

FIG. 7. Tangential section of scleral spur cells in an 84-year-old human. When compared with the scleral spur cells of younger humans, the annount of 5-6 nm thin filaments (arrowheads) is reduced and numerous profiles of rough endoplasmic reticulum, ribosomes and Golgi material are present instead (arrows). Sheath material with a $50-\mathrm{nm}$ and $100-\mathrm{nm}$ periodicity surrounds the scleral spur cells in increased amounts. $\times 8100$.

connections with the elastic-like fibres, which are similar to those of the SSC.

Eyes of old humans (68-87 years). The elastic-like fibres of the scleral spur show marked age-related changes. The sheath material containing banded fibres with a $50-\mathrm{nm}$ and a $100-\mathrm{nm}$ periodicity is significantly increased; interlacing elastic-like fibres often surround the SSC and the ciliary muscle cells at their anterior insertion (Fig. 7). In the region of the tendon-like contacts, no 12-14 nm extracellular microfibrils are seen. but the 50-nm and 100-nm banded sheath material is in close contact with both the SSC and the ciliary muscle cells. The SSC also show ultrastructural changes, when compared with the cells of the younger eyes. The amount of 5-6 nm thin filaments within their cytoplasm seems to be reduced and numerous profiles of rough endoplasmic reticulum, ribosomes and Golgi material are present instead (Fig. 7). Additionally. several cells contain numerous lysosomes.

Cynomolgus monkeys ( $2-4$ years). The architecture of the scleral spur and the anterior ciliary muscle attachment in young adult monkeys is very similar to that of young humans. The morphology of the elasticlike fibres differs, in so far as the banded sheath material is less frequently observed. Only where the elastic microfibrils are connected to the SSC by fine fibrillous material is banded sheath material (fibrous long-spacing collagen, curly or lattice collagen) with a periodicity of $100 \mathrm{~nm}$ occasionally observed [Fig. $8(A)]$. The ultrastructure of the SSC is similar to that of young humans, except that large inclusions of glycogen particles are often found [Fig. 8(B)].

\section{Discussion}

The presence of a well-developed scleral spur is rcgarded as a characteristic feature of the chamber angle of the human eye (Franz, 1934; Rohen, 1964, 1982). Our study reveals a circular system of cells within the scleral spur ('scleral spur cells'; SSC). The SSC are distinct from ciliary muscle cells and have previously been considered to be fibroblasts (Iwamoto, 1964). Our results, however, show that the SSC are in fact myofibroblasts which closely resemble the myofibroblasts described in other tissues, e.g. the external theca of the ovarian follicle (O'Shea, 1970: Czernohilsky et al.. 1989), the duodenal villi (Güldner. Wolff and Keyserlingk, 1972) and the pulmonary alveolar septa (Kapanci et al., 1974). All types of myofibroblasts studied so far are contractile (for review see Skalli and Gabbiani. 1988). so that we assume the 

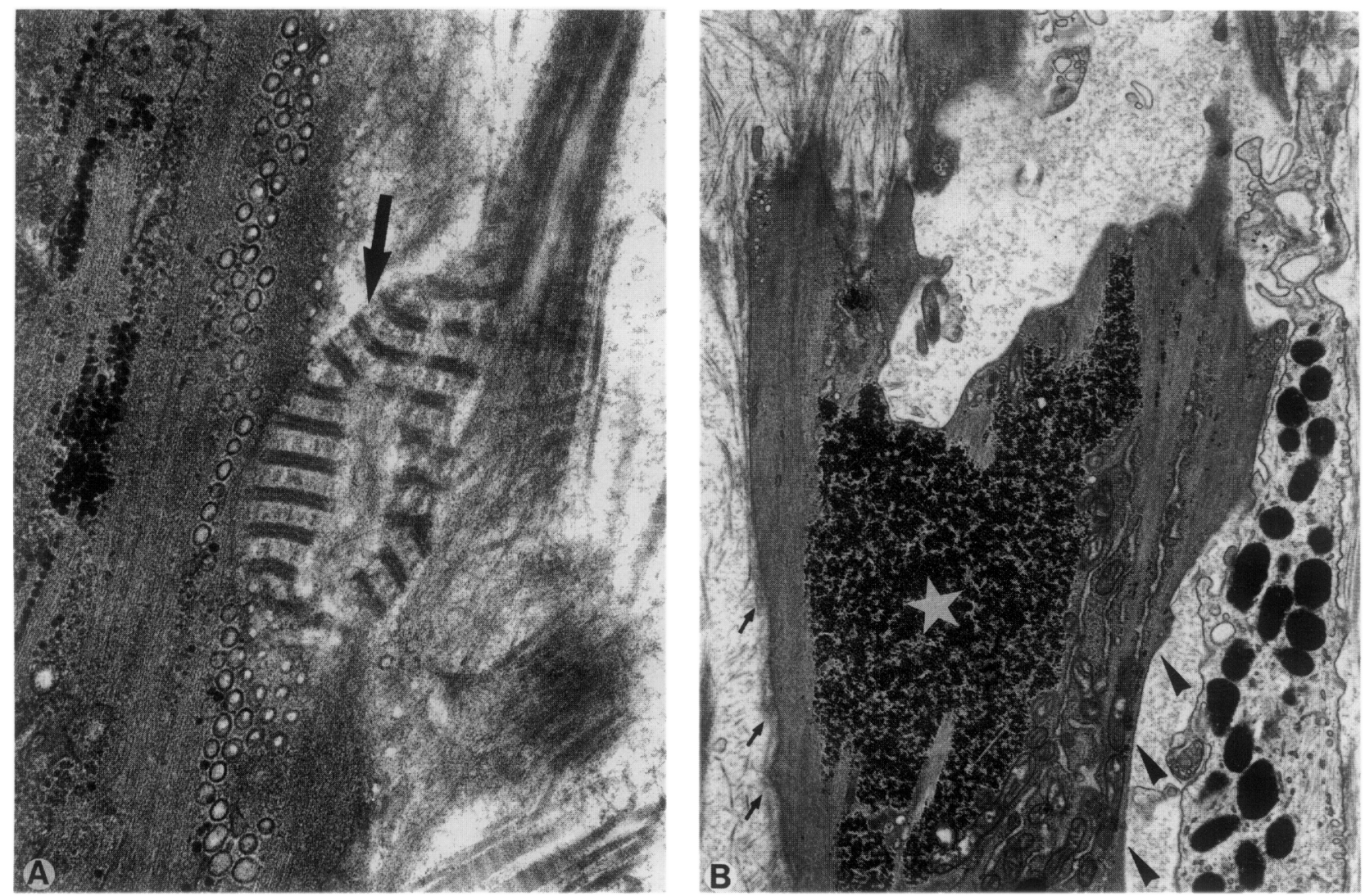

FIG. 8. Scleral spur cells in cynomolgus monkeys. A, Only where the elastic microfibrils are connected to the scleral spur cells is banded sheath material (long-spacing collagen) with a periodicity of $100 \mathrm{~nm}$ occasionally observed. $\times 38000$. B, The scleral spur cells often contain large amounts of glycogen (asterisk). Similar to human scleral spur cells, the basal lamina (arrows) is incomplete and leaves large parts of the cell membrane uncovered (arrowheads). $\times 11900$.

same is true for the SSC. The evidence in support of this hypothesis is as follows. The SSC share the typical ultrastructural features of myofibroblasts. They normally contain numerous longitudinal bundles of microfilaments with scattered dense bodies in between. which have been shown to represent actin containing stress fibres (Darby, Skalli and Gabbiani, 1990). In addition, the SSC stain uniformly with markers generally accepted to discriminate smooth muscle cells and myofibroblasts from fibroblasts (Darby, Skalli and Gabbiani, 1990). Antibodies against the smooth muscle $\alpha$-actin isoform (Vanderkerckhove and Weber, 1979) have been shown specifically to strain smooth muscle cells of different origins as well as myofibroblasts (Skalli et al., 1986, 1987; Czernobilsky et al., 1989; Darby et al., 1990; Flügel et al., 1991).

In the scleral spur, the presence of smooth-muscle myosin positive cells was also recently described by de Kater et al. (1990). The authors regarded these cells as ciliary muscle cells. There are, however, several distinctive features which show that these cells are SSC and not ciliary muscle cells. The ciliary muscle cells are the only cells of the chamber angle region which stain for desmin; this is generally regarded as the intermediate filament specific for striated muscle and visceral smooth muscle cells (Osborn and Weber, 1983). SSC do not stain for desmin but only for the intermediate filament vimentin, as do other myofibro- blasts (Skalli and Gabbiani, 1988; Darby et al., 1990). In addition, the SSC do not show the typical ultrastructural features of ciliary muscle cells (Ishikawa, 1962 ; van der Zypen, 1967 ; Lütjen-Drecoll et al., 1988; Flügel, Bárány and Lütjen-Drecoll, 1990) such as the large number of mitochondria, and the dense bands which form a right angle with the myofilaments in the periphery. Furthermore, the SSC are not aggregated into bundles and do not express a complete basal lamina. Similar to the fibroblasts in the anterior sclera and the iris stroma (Raviola, Sagaties and Miller, 1987), they are connected by gap junctions which have not been found in ciliary muscle so far either by freeze fracture (Raviola et al., 1987) or transmission electron microscopy (Lütjen-Drecoll et al., 1988: Tamm, Lütjen-Drecoll and Rohen, 1990). In summary, our findings strongly suggest that the SSC form a contractile cell population which differs from the ciliary muscle.

It has been reported that the scleral spur is thicker in the eyes of older humans (Fischer, 1933). Similar to the elastic-like fibres in the human trabecular meshwork (Lütjen-Drecoll et al., 1982, 1986a) and the anterior part of the ciliary muscle (Lütjen-Drecoll et al., 1986b), there is a pronounced increase with age of the sheath-material in the elastic-like fibres of the scleral spur. It might be that the myofibroblasts are responsible for the accumulation of the extracellular 
matrix in this region. In fact, the ultrastructure of the SSC was found to change with age. In old human eyes, the SSC contained fewer myofilaments and more rough endoplasmic reticulum and an enlarged Golgi system. A similar switch to a synthetic phenotype has been reported for vascular smooth muscle cells under conditions which are accompanied by increased production of extracellular matrix, for example experimental aortic thickening induced by endothelial injury (Poole. Cromwell and Benditt, 1971; Kocher et al., 1984).

In general, it seems that in myofibroblasts, contraction and relaxation is slower than in smooth muscle cells. Whether or not they can maintain tension is not clear. Myofibroblasts in other tissues show contractile responses to several neurotransmitters and many pharmacological agents. However, the reactivity differs from organ to organ and between stimulating agents (for review see Skalli and Gabbiani, 1988). The SSC certainly do not show the extremely densc innervation of the ciliary musclc (Ishikawa, 1962; van der Zypen, 1967; Townes-Anderson and Raviola, 1976, 1978). Close to the SSC we found nerve terminals containing small agranular vesicles $(30-50 \mathrm{~nm})$ and large granular vesicles $(65-100 \mathrm{~nm})$. We also observed nerve terminals containing small granular vesicles, although our fixation was not optimal for their preservation (Richardson, 1966; Nishida and Sears, 1969). Such terminals are regarded as typical for adrenergic nerve endings (Uehara, Campbell and Burnstock, 1976; Ruskell, 1982). Adrenergic nerves were not observed in the scleral spur by light microscopical observation of catecholamine fluorescence (Ehinger, 1966, 1971; Laties and Jacobowitz, 1966). The authors reported, however, that the strong autofluorescence of this region proved a considerable hindrance. However, numerous adrenergic nerve terminals have been identified electron microscopically in the scleral spur of cynomolgus monkeys after labelling with 5-hydroxydopamine (Normura and Smelser, 1974). Although the origin and nature of the innervation of the SSC has to be clarified further, the possibility exists that the SSC are, at least partly, adrenergic innervated cells. Kaufman and Bárány (1981) studied adrenergic drug effects on outflow facility in cynomolgus monkey eyes after surgical disinsertion of the ciliary muscle. In these eyes, where the scleral spur and its attachment to the trabecular meshwork remained intact (Lütjen-Drecoll, Kaufman and Bárány, 1977), epinephrine still increased outflow facility. The present findings suggest the possibility that the SSC may be involved in the effects of epinephrine on outflow facility in the primate eye.

\section{Acknowledgements}

We would like to thank Simone Klein and Gertrud Link for their expert assistance in electron microscopy and Ute
Maurer for her excellent help in immunocytochemistry. We would also like to thank Marco Gößwein for his excellent preparation of the photographs. This study was supported by grants Dre 124/6-1 and Ro 81/18-4 from the Deutsche Forschungsgemeinschaft.

\section{References}

Czernobilsky. B.. Shezen. E., Lifschitz-Mercer, B., Fogel. M.. Luzon, A., Jacob, N., Skalli, O. and Gabbiani, G. (1989). Alpha smooth muscle actin ( $\alpha$-SM actin) in normal human ovaries, in ovarian stromal hyperplasia and in ovarian neoplasms. Virchows Archiv. B Cell Pathol. 57, 55-61.

Darby, I., Skalli, O. and Gabbiani, G. (1990). $\alpha$-Smooth muscle actin is transiently expressed by myofibroblasts during experimental wound healing. Lab. Invest. 63 21-9.

de Kater, A. W., Spurr-Michaud, S. J. and Gipson, I. K. (1990). Localization of smooth muscle myosin-containing cells in the aqueous outflow pathway. Invest. Ophthalmol. Vis. Sci. 31, 347-53.

Debus, E., Weber, K. and Osborn, M. (1983). Monoclonal antibodies to desmin, the muscle-specific intermediate filament protein. EMBO J. 2, 2305-12.

Duhamel, R. C. and Johnson, D. A. (1985). Use of nonfat dry milk to block nonspecific nuclear and membrane staining by avidin conjugates. J. Histochem. Cytochem. 33. 711-14.

Ehinger, B. (1966). Adrenergic nerves to the eye and to related structures in man and in the Cynomolgus monkey. Invest. Ophthalmol. Vis. Sci. 5, 42-52.

Ehinger, B. (1971). A comparative study of the adrenergic nerves to the anterior eye segment of some primates. $Z$. Zellforsch. 116, 157-77.

Fischer, F. (1933). Entwicklungsgeschichtliche und anatomische Studien über den Skleralsporn im menschlichen Auge. Graefe's Arch. Clin. Exp. Ophthalmol. 133. 318-58.

Flocks, M. and Zweng, C. (1957). Studies on the mode of action of pilocarpine on aqueous outflow. Am. J. Ophthalmol. 44, 380-7.

Flügel. C., Bárány, E. H. and Lütjen-Drecoll. E. (1990). Histochemical differences within the ciliary muscle and its function in accommodation. Exp. Eye Res. 50, 219-26.

Flügel, C., Tamm, E. and Lütjen-Drecoll, E. (1991). Different cell populations in trabecular meshwork: an ultrastructural and immunohistochemical study. Exp. Eye Res. 52, 681-90.

Franz. V. (1934). III. Höhere Sinnesorgane. 1. Vergleichende Anatomie des Wirbeltierauges. In Handbuch der vergleichenden Anatomie der Wirbeltiere. (Eds Bolk, L., Göppert. E.. Kallius. E. and Lubosch. W.\}. Pp. 1009-23. Urban \& Schwarzenberg: Berlin.

Grierson, I.. Lee, W. R. and Abraham, S. (1978). Effects of pilocarpine on the morphology of the human outflow apparatus. Br. J. Ophthalmol. 62, 302-13.

Güldner, F. H.. Wolff. J. R. and Keyserlingk. D. (1972). Fibroblasts as part of the contractile system in duodenal villi of the rat. Z. Zellforsch. 135, 349-60.

Ishikawa, T. (1962). Fine structure of the human ciliary muscle. Invest. Ophthalmol. Vis. Sci. 1, 587-608.

Ito, S. and Karnovsky, M. J. (1968). Formaldehydeglutaraldehyde fixatives containing trinitro compounds. J. Cell Biol. 39, 168A-9A.

Iwamoto, T. (1964). Light and electron microscopy of the presumed elastic components of the trabeculae and scleral spur of the human eye. Invest. Ophthalmol. Vis. Sci. 3, 144-56. 
Johnson, G. D., Davidson, R. S.. McNamee, K. C.. Russel. G., Goodwin, D. and Holborow, E. J. (1982). Fading of immunofluorescence during microscopy: a study of the phenomenon and its remedy. J. Immunol. Methods 55. $231-42$.

Kapanci, Y., Assimacopoulos, A., Irle, C., Zwahlen, A. and Gabbiani G. (1974). 'Contractile interstitial cells' in pulmonary septa. J. Cell Biol. 60, 375-92.

Kaufman, P. L. and Bárány, E. H. (1976). Loss of acute pilocarpine effect on outflow facility following surgical disinsertion and retrodisplacement of the ciliary muscle from the scleral spur in the cynomolgus monkey. Invest. Ophthalmol. Vis. Sci. 15, 793-807.

Kaufman. P. L. and Bárány, E. H. (1981). Adrenergic drug effects on aqueous outflow facility following ciliary muscle retrodisplacement in the cynomolgus monkey. Invest. Ophthalmol. Vis. Sci. 20, 644-51.

Kocher, O.. Skalli, O., Bloom, W. S. and Gabbiani, G. (1984). Cytoskeleton of rat aortic smooth muscle cells. Normal conditions and experimental intimal thickening. Lab. Invest. 50, 645-52.

Laties, A. and Jacobowitz, D. (1966). A comparative study of the autonomic innervation of the eye in monkey, cat and rabbit. Anat. Rec. 156, 383-96.

Lütjen-Drecoll, E., Dietl, T.. Futa, R. and Rohen, J. W. (1982). Age changes of the trabecular meshwork. A preliminary morphometric study. In The Structure of the Eye. (Ed. Hollyfield, J. G.). Pp. 341-8. Elsevier North Holland: New York.

Lütjen-Drecoll, E., Futa, R. and Rohen, J. W. (1981). Ultrahistochemical studies on tangential sections of the trabecular meshwork in normal and glaucomatous eyes. Invest. Ophthalmol. Vis. Sci. 21, 563-73.

Lütjen-Drecoll, E., Kaufman. P. L. and Bárány, E. H. (1977). Light and elestron microscopy of the anterior chamber angle structures following surgical disinsertion of the ciliary muscle in the cynomolgus monkey. Invest. Ophthalmol. Vis. Sci. 16, 218-25.

Lütjen-Drecoll, E., Shimizu, T., Rohrbach, M. and Rohen, J. W. (1986a). Quantitative analysis of 'plaque material' in the inner and outer wall of Schlemm's canal in normal and glaucomatous eyes. Exp. Eye Res. 42, $443-55$.

Lütjen-Drecoll, E., Shimizu, T., Rohrbach, M. and Rohen, J. W. (1986b). Quantitative analysis of 'plaque-material' between ciliary muscle tips in normal and glaucomatous eyes. Exp. Eye Res. 42, 457-65.

Lütjen-Drecoll, E., Tamm, E. and Kaufman, P. L. (1988). Age changes in rhesus monkey ciliary muscle: light and electron microscopy. Exp. Eye Res. 47. 885-99.

McLean, I. W. and Nakane. P. K. (1974). Periodate-lysineparaformaldehyde fixative: a new fixative for immunoelectron microscopy. J. Histochem. Cytochem. 22, $1077-83$.

Nishida, S. and Sears, M. (1969). Fine structural innervation of the dilator muscle of the iris of the albino guinea-pig studied with permanganate fixation. Exp. Eye Res. 8. 292-6.

Nomura, T. and Smelser, G. K. (1974). The identification of adrenergic and cholinergic nerve endings in the trabecular meshwork. Invest. Ophthalmol. Vis. Sci. 13. 525-32.

O'Shea, J. (1970). An ultrastructural study of smooth muscle-like cells in the theca externa of the ovarian follicle in the rat. Anat. Rec. 167, 127-31.

Osborn, M., Debus, E. and Weber, K. (1984). Monoclonal antibodies specific for vimentin. Eur. J. Cell Biol. 34, $137-43$.

Osborn, M. and Weber, K. (1983). Tumor diagnosis by intermediate filament typing: a novel tool for surgical pathology. Lab. Invest. 48, 372-94.
Poole, J. C., Cromwell, S. B. and Benditt, E. P. (1971). Behavior of smooth muscle cells and formation of extracellular structures in the reaction of arterial wall to injury. Am. J. Pathol. 62, 391-414.

Raviola, G., Sagaties, M. J. and Miller, C. (1987). Intercellular junctions between fibroblasts in connective tissues of the eyes of macaque monkeys. A thin section and freeze fracture analysis. Invest. Ophthalmol. Vis. Sci. $28,834-41$.

Richardson, K. C. (1966). Electron microscopic identification of autonomic nerve endings. Nature 210, 756.

Richardson. K. C., Jarret, L. and Finke, H. (1960). Embedding in epoxy resins for ultrathin sectioning in electron microscopy. Stain Technol. 35, 313-23.

Rohen, J. W. (1964). Ciliarkörper (Corpus ciliare). In Handbuch der mikroskopischen Anatomie des Menschen. Vol. 3. pt. 4, Haut und sinnesorgane. Das Auge und seine Hilfsorgane. (Eds Möllendorf, W. v. and Bargmann, W.). Pp. 189-237. Springer Verlag: Berlin. New York.

Rohen, J. W. (1982). The evolution of the primate eye in relation to the problem of glaucoma. In Basic Aspects of Glaucoma Research. (Ed. Lütjen-Drecoll, E.). Pp. 3-33. Schattauer Verlag: Stuttgart, Germany.

Rohen, J. W., Futa, R. and Lütjen-Drecoll, E. (1981). The fine structure of the cribriform meshwork in normal and glaucomatous eyes as seen in tangential sections. Invest. Ophthalmol. Vis. Sci. 21, 574-85.

Rohen. J. W. and Unger, H.-H. (1958). Studies on the morphology and pathology of the trabecular meshwork in the human eye. Am. J. Ophthalmol. 46, 802-13.

Rohen, J. W. and Unger, H.-H. (1959). Zur Morphologie und Pathologie der Kammerbucht des Auges. Abh. Mainzer Akad. der Wiss., math.-nat. Kl., Pt. 3. Franz Steiner: Wiesbaden. Germany.

Romeis. B. (1989). Mikroskopische Technik. 17th edn. (Ed. Böck, P.). Pp. 517-22. Urban \& Schwarzenbeck: München, Raltimore.

Ruskell, G. L. (1982). Innervation of the anterior segment of the eye. In Basic Aspects of Glaucoma Research. (Ed. Lütjen-Drecoll. E.). Hp. 49-66. Schattauer: Stuttgart, Germany.

Skalli, O. and Gabbiani. G. (1988). The biology of the myofibroblast: relationship to wound contraction and fibrocontractive diseases. In The Molecular and Cellular Biology of Wound Repair. (Eds Clark, R. A. F. and Henson, P. M.). Pp. 373-402. Plenum: New York.

Skalli, O., Ropraz, P., Trzeciak, A., Benzonana, G., Gillessen, D. and Gabbiani, G. (1986). A monoclonal antibody against $\alpha$-smooth muscle actin : a new probe for smooth muscle differentiation. J. Cell Biol. 103, 2787-96.

Skalli, O., Vanderkerckhove, J. and Gabbiani, G. (1987). Actin isoform pattern as a marker of normal or pathological smooth muscle and fibroblastic tissues. Differentiation 33, 232-38.

Tamm, E., Lütjen-Drecoll, E. and Rohen, J. W. (1990). Agerelated changes of the ciliary muscle in comparison with changes induced by treatment with prostaglandin $\mathrm{F}_{2 x}$. An ultrastructural study in rhesus and cynomolgus monkeys. Mech. Ageing Develop. 51, 101-20.

The Association for Research in Vision and Ophthalmology (1990). Statement for the Use of Animals in Research. Invest. Ophthalmol. Vis. Sci. 31, 1416-18.

Townes-Anderson, E. and Raviola, G. (1976). Giant nerve fibers in the ciliary muscle and iris sphincter of Macaca mulatta. Cell Tissue Res. 169, 33-40.

Townes-Anderson, E. and Raviola, G. (1978). Degeneration and regeneration of autonomic nerve endings in the anterior part of rhesus monkey ciliary muscle. I. Neurocytol. 7, 583-600.

Uehara, Y., Campbell, G. R. and Burnstock, G. (1976). 
Muscle and its Innervation. An Atlas of Fine Structure. Edward Arnold: London.

Vanderkerckhove, J. and Weber, K. (1979). The complete amino acid sequence of actins from bovine aorta, bovine heart, bovine fast skeletal muscle and rabbit slow skeletal muscle. Differentiation 14, 123-33.

Van der Zypen, E. (1967). Licht- und elektronenmikro- skopische Untersuchungen über den Bau und die Innervation des Ziliarmuskels bei Mensch und Affe (Cercopithecus aethiops). Graefes Arch. Clin. Exp. Ophthalmol 174. 143-68.

Vegge, T. and Ringvold, A. (1971). The ultrastructure of the extracellular components of the trabecular meshwork in the human eye. Z. Zellforsch. 115, 361-76. 